\title{
O CUIDADO COM O IDOSO FRAGILIZADO E A ESTRATÉGIA SAÚDE DA FAMÍLIA: PERSPECTIVAS DO CUIDADOR INFORMAL FAMILIAR
}

\author{
CARE FOR FRAGILE ELDERLY PEOPLE \\ AND THE FAMILY HEALTH STRATEGY: \\ PERSPECTIVES OF CAREGIVERS
}

\section{ATENCIÓN AL ADULTO MAYOR FRÁGIL Y ESTRATEGIA DE SALUD DE LA FAMILIA: PERSPECTIVAS DE LOS CUIDADORES}

\author{
Mírian Aparecida de Lacerda ${ }^{1}$ \\ Liliane de Lourdes Teixeira Silva ${ }^{2}$ \\ Flávia de Oliveira $^{3}$ \\ Kellen Rosa Coelho ${ }^{4}$
}

Como citar este artigo: Lacerda MA, Silva LLT, Oliveira F, Coelho KR. O cuidado com o idoso fragilizado e a Estratégia Saúde da Família: perspectivas do cuidador informal familiar. Rev baiana enferm. 2021;35:e43127.

\begin{abstract}
Objetivo: compreender o cuidado com o idoso fragilizado prestado por cuidadores informais familiares, bem como a interação destes com a Estratégia Saúde da Família, na perspectiva dos cuidadores. Método: estudo exploratório-descritivo, qualitativo, realizado com 17 cuidadores informais familiares de idosos fragilizados de uma Estratégia Saúde da Família de Minas Gerais, Brasil. Dados coletados entre setembro/2019 e fevereiro/2020, mediante entrevista com roteiro semiestruturado e questionário. Realizou-se análise de conteúdo, tipo temática. Resultados: maioria dos cuidadores eram mulheres, 26-79 anos, brancas e pardas, casadas e baixa escolaridade. Comunicação efetiva entre equipe de saúde e cuidador familiar/idoso, em detrimento de alta rotatividade de profissionais da Estratégia Saúde da Família, demanda excessiva de funções e falta de capacitação e habilidade técnica do cuidador. Considerações finais: cuidado com idoso fragilizado pertencia ao universo feminino e suscitava um misto de sentimentos. Interação entre cuidadores e Estratégia Saúde da Família acontecia geralmente mediada pelo Agente Comunitário de Saúde.
\end{abstract}

Descritores: Saúde do Idoso. Estratégia Saúde da Família. Cuidadores. Idoso Fragilizado. Enfermagem.

Objective: to understand the care for the frail elderly provided by family-related inpatient caregivers, as well as their interaction with the Family Health Strategy, from the perspective of caregivers. Method: exploratory-descriptive, qualitative study conducted with 17 informal family-related caregivers of frail elderly from a Family Health Strategy in Minas Gerais, Brazil. Data collected between September/2019 and February/2020, through an interview with semi-structured script and questionnaire. Content analysis was performed, thematic type. Results: most caregivers

\footnotetext{
Enfermeira. Residente no Programa de Residência Profissional em Enfermagem na Atenção Básica/Saúde da Família da Universidade Federal de São João Del Rei, Campus Centro-Oeste Dona Lindu. Divinópolis, Minas Gerais, Brasil. https://orcid.org/0000-0003-3312-6948.

Enfermeira. Doutora em Ciências da Saúde. Professora Adjunta da Universidade Federal de São João Del Rei, Campus Centro-Oeste Dona Lindu. Divinópolis, Minas Gerais, Brasil. https://orcid.org/0000-0002-3429-3310.

Enfermeira. Doutora em Enfermagem. Professora Adjunta da Universidade Federal de São João Del Rei, Campus Centro-Oeste Dona Lindu. Divinópolis, Minas Gerais, Brasil. https://orcid.org/0000-0002-9044-6588.

${ }^{4}$ Enfermeira. Doutora em Enfermagem. Professora Adjunta da Universidade Federal de São João Del Rei, Campus Centro-Oeste Dona Lindu. Divinópolis, Minas Gerais, Brasil. kellencoelho@ufsj.edu.br. https://orcid.org/0000-0002-8629-8367.
} 
were women, 26-79 years old, white and brown, married and low schooling. Effective communication between the bealth team and the family/elderly caregiver, to the detriment of high turnover of professionals of the Family Health Strategy, excessive demand for functions and lack of training and technical ability of the caregiver. Final thoughts: care for the frail elderly belonged to the female universe and aroused a mixture of feelings. Interaction between caregivers and family health strategy was generally mediated by the Community Health Agent.

\section{Descriptors: Elderly Health. Family Health Strategy. Caregivers. Fragile Elderly. Nursing.}

Objetivo: comprender el cuidado de los ancianos frágiles proporcionado por los cuidadores internados relacionados con la familia, así como su interacción con la Estrategia de Salud de la Familia, desde la perspectiva de los cuidadores. Método: estudio exploratorio-descriptivo, cualitativo, realizado con 17 informadores familiares de ancianos frágiles de una Estrategia de Salud de la Familia en Minas Gerais, Brasil. Datos recolectados entre Septiembre/2019y Febrero/2020, a través de una entrevista con guión semiestructurado y cuestionario. Se realizó un análisis de contenido, tipo temático. Resultados: la mayoría de los cuidadores eran mujeres, de 26 a 79 años, blancas y marrones, casadas y de baja escolaridad. Comunicación efectiva entre el equipo de salud y el cuidador familiar/anciano, en detrimento de la alta rotación de profesionales de la Estrategia de Salud de la Familia, la excesiva demanda de funciones y la falta de capacitación y capacidad técnica del cuidador. Consideraciones finales: el cuidado de los ancianos frágiles pertenecía al universo femenino y despertaba una mezcla de sentimientos. La interacción entre los cuidadores y la estrategia de salud de la familia fue generalmente mediada por el Agente Comunitario de Salud.

Descriptors: Salud del Anciano. Estrategia de Salud de la Familia. Cuidadores. Ancianos Frágiles. Enfermería.

\section{Introdução}

É notório o aumento considerável da população idosa no Brasil ao longo dos anos. Conforme preveem as estatísticas, o número de idosos entre 1950 e 2025 aumentará em quinze vezes, ao passo que a população total, em cinco ${ }^{(1)}$. Em paralelo ao aumento da expectativa de vida, sobretudo decorrente dos avanços tecnológicos que ampliam a possibilidade do tempo de vida, as Doenças Crônicas Não Transmissíveis (DCNTs) tornaram-se as principais comorbidades e até causas de morte desse grupo etário ${ }^{(2)}$.

Juntamente com a transição demográfica, o envelhecimento da população e a alta carga de DCNTs nos idosos, surge maior demanda por cuidados inerentes à saúde dessa população. Tal demanda dá-se, sobretudo, pela alta vulnerabilidade e fragilização, com consequente declínio funcional, o qual pode diminuir o convívio social, interferir na qualidade de vida e desestruturar a dinâmica familiar dos idosos ${ }^{(3)}$.

A definição de fragilização do idoso ainda é bastante controversa na literatura, embora seja utilizada para descrever o idoso com maior risco de incapacidades, institucionalização, hospitalização e morte ${ }^{(4)}$. A fragilidade multidimensional do idoso é decorrente da deterioração de fatores biológicos, psicológicos e sociais ao longo da vida ${ }^{(5)}$. Estes fatores estão relacionados, por exemplo, a aspectos como a redução da força muscular, lentificação da marcha, aumento da idade, sexo feminino, baixo nível socioeconômico, presença de comorbidades (sobretudo DCNTs), funcionalidade global (cognição, humor e comunicação), além de outros indicadores de mau prognóstico, como a presença de polipatologia, polifarmácia, internação hospitalar recente e risco psicosociofamiliar elevado (insuficiência familiar) ${ }^{(4)}$.

$\mathrm{Na}$ perspectiva da funcionalidade, a presença de declínio funcional no idoso configura-se como o principal determinante da presença de fragilidade $^{(4)}$. O declínio funcional, por sua vez, segundo a Classificação Internacional da Funcionalidade $^{(6)}$, é a perda da autonomia e/ou da independência, o que restringe a participação social do indivíduo e compromete o desenvolvimento das atividades de vida diárias (avançadas, instrumentais e básicas).

Além da interferência das DCNTs, o declínio funcional no idoso é causado, sobretudo, pelas principais síndromes associadas ao envelhecimento, conhecidas como as Grandes Síndromes 
Geriátricas: incapacidade cognitiva, instabilidade postural, incontinência esfincteriana, imobilidade e incapacidade comunicativa. A presença dessas condições crônicas de saúde aumenta a demanda de cuidados e a complexidade do manejo clínico, com consequente risco de iatrogenia. Além disso, estão associadas a maior demanda de cuidados de longa duração, usualmente realizados pela família, que, na maioria das vezes, não se encontra preparada para esta nova função, quando se apresenta a insuficiência familiar ${ }^{(4)}$.

O idoso portador de doença crônica, degenerativa ou incapacitante, quando não necessita de assistência nos serviços de saúde, seja da atenção primária, seja da atenção secundária e terciária, é cuidado no domicílio por um cuidador formal ou informal. O cuidador formal é aquele que recebe remuneração pelos serviços prestados, é capacitado para reconhecer e diferenciar as necessidades do idoso, para lidar com doenças e seus sintomas cognitivos ou sociais, tanto pessoais quanto familiares, bem como ajudar nas atividades de vida diária. Já o cuidador informal é um familiar ou pessoa da comunidade, que recebe ou não remuneração para prestar cuidados em pessoas com limitações físicas ou mentais e não é necessariamente capacitado para tal ${ }^{(7)}$.

É muito comum que esse cuidador informal seja um membro da família do idoso. Muitas famílias, por não terem condição financeira para arcar com despesas de um profissional para desempenhar a função de cuidador, acabam optando por trazer o idoso para o seio familiar e tornam-se os principais responsáveis pelo seu cuidado $^{(3)}$. Vale salientar que, predominantemente, quem desempenha este papel de cuidador informal acaba sendo algum indivíduo do sexo feminino com vínculo familiar com o idoso, a exemplo de cônjuge ou filha ${ }^{(3)}$. Um aspecto muito comum é este cuidador informal familiar já ser também um idoso ${ }^{(8)}$.

De fato, suprir essa demanda de cuidados do idoso com a saúde debilitada requer do cuidador familiar, muitas vezes, uma reorganização da sua própria rotina, porém nem sempre esse ajuste das atividades cotidianas é alcançado, o que leva a sentimentos de angústia, tensão e sobrecarga ${ }^{(3)}$.
O acúmulo de atividades domésticas, a falta de informações adequadas para o cuidado e de treinamento de habilidades por parte do familiar que cuida propicia estresse e exaustão, com consequente aumento da sobrecarga física e mental desse cuidador e de conflitos familiares ${ }^{(9)}$.

Para mitigar esses aspectos, sobretudo no concernente à falta de informações e habilidades para o cuidado com o idoso fragilizado, a Estratégia Saúde da Família (ESF), por meio da longitudinalidade do cuidado e da equipe multidisciplinar, pode e deve oferecer suporte às necessidades do idoso e do cuidador/família no âmbito da Atenção Primária à Saúde (APS), conforme preconizado pela Política Nacional da Atenção Básica (PNAB) de $2017^{(10)}$.

Destarte, tendo em vista a conformação da APS com a abrangência e significativa atuação na promoção da saúde, prevenção de agravos, controle e tratamento de doenças, é primordial a dispensação de atenção integral à saúde do idoso no manejo das comorbidades, sobretudo das DCNTs, e das incapacidades funcionais para melhoria da qualidade de vida dessa população ${ }^{(2)}$. Além disso, do ponto de vista da assistência ao idoso fragilizado no âmbito da APS, a ESF exerce papel fundamental na orientação e instrumentalização dos cuidadores familiares, para que o cuidado, desempenhado com assertividade, seja capaz de mitigar os impactos na saúde desses cuidadores ${ }^{(11)}$.

Entretanto, ampliar o olhar para além do idoso e suas comorbidades e/ou incapacidades no contexto da APS é um grande desafio na integralidade do cuidado por parte da ESF. Nota-se a necessidade de os profissionais expandirem o olhar para o cuidador familiar ${ }^{(11)}$. Neste sentido, é extremamente relevante compreender o cuidado diante do binômio cuidador-idoso fragilizado e interagir assertivamente com este familiar que cuida. Nesta perspectiva, torna-se relevante investigar o perfil dos cuidadores, bem como averiguar como se configura o cuidado com o idoso fragilizado e como se dá a interação entre equipe de ESF e cuidador informal familiar, na percepção desse cuidador.

Informações advindas desta investigação poderão balizar reflexões e discussões entre 
os profissionais da ESF, sobretudo a equipe de enfermagem e, consequentemente, favorecer o planejamento e a implementação de ações direcionadas para a melhoria da saúde dos idosos fragilizados e das condições de cuidado dos cuidadores familiares. Ademais, a compreensão deste cuidado pode estimular a equipe de saúde a obter ações resolutivas nos atendimentos ao idoso fragilizado e seu cuidador, especialmente nas visitas domiciliares.

Dessa forma, o objetivo deste estudo foi compreender o cuidado com o idoso fragilizado prestado por cuidadores informais familiares, bem como a interação destes com a ESF, na perspectiva dos próprios cuidadores.

\section{Método}

Trata-se de um estudo exploratório-descritivo, com abordagem qualitativa, desenvolvido com cuidadores informais familiares dos idosos fragilizados residentes na área de abrangência de uma ESF localizada na periferia de um município da região Centro-Oeste de Minas Gerais, Brasil. Considerou-se idoso fragilizado aquele que possuía alguma incapacidade de ordem cognitiva, de humor, de mobilidade e/ou comunicativa que interferisse na capacidade de executar as atividades de vida diária com autonomia e independência $^{(4)}$.

A amostra do estudo foi por conveniência, pois a proposta foi abranger todos os 21 cuidadores familiares dos idosos fragilizados elegíveis da área pertencente à ESF supracitada, da qual uma das pesquisadoras era membro da equipe de saúde. No entanto, desse total, participaram 17 cuidadores, pois a coleta de dados precisou ser interrompida, devido ao início da pandemia de COVID-19 no Brasil. Como critérios de inclusão, foram elencados: ser cuidador familiar de idoso fragilizado e ter idade superior a 18 anos. O critério de exclusão adotado foi o cuidador ser remunerado para o cuidado dispensado ao idoso.

Os dados foram coletados entre setembro de 2019 e fevereiro de 2020, por uma enfermeira residente em Enfermagem na Atenção Básica/Saúde da Família atuante na referida ESF, por meio de entrevista com a utilização de um questionário estruturado (preenchido pela entrevistadora), para investigar o perfil sociodemográfico e as condições de saúde e de lazer. Utilizou-se também um roteiro semiestruturado com questões norteadoras, as quais abordaram o cuidado diário com o idoso fragilizado e a interação do cuidador informal familiar com a ESF. As entrevistas duraram, em média, 20 minutos. Foram gravadas após autorização dos participantes, quando teve início a abordagem do roteiro semiestruturado. As gravações foram transcritas na íntegra.

Antes da realização da entrevista, o cuidador foi contactado previamente, por meio de visita domiciliar, para ser informado sobre a pesquisa. Após aceite, foram agendados o dia e o horário para a coleta de dados, a qual aconteceu nos respectivos domicílios, de forma individual e em local privativo. Respeitou-se o anonimato dos participantes, identificando-os pela sigla CI (para cuidador informal) seguida do número correspondente à ordem de realização da entrevista: CI-1, CI-2... CI-15. Vale esclarecer que as entrevistas realizadas, apesar de não abrangerem o total de participantes, atingiram a saturação dos dados, garantindo a validade da amostra.

A organização e análise descritiva dos dados quantitativos provenientes do questionário sociodemográfico e de condições de saúde e de lazer foram realizadas no programa Epi Info versão 7.2.3.1, calculando-se as frequências absolutas e relativas para caracterização dos participantes.

Para analisar os dados qualitativos, foi utilizada a análise de conteúdo do tipo temática ${ }^{(12)}$. Este tipo de análise permite identificar os núcleos de sentido da comunicação e constitui-se de três etapas: pré-análise; exploração do material; tratamento dos resultados, inferência e interpretação. Inicialmente, realizou-se a leitura flutuante das entrevistas, das quais emergiram as unidades de significado. Na segunda etapa, a organização das unidades de significado deu origem a duas categorias.

Este estudo, submetido ao Comitê de Ética em Pesquisa com Seres Humanos da Universidade Federal de São João del Rei - Campus Centro-Oeste Dona Lindu, foi aprovado pelo Parecer 
n. 3.516.178 e Certificado de Apresentação para Apreciação Ética (CAAE) n. 18509019.3.0000.5545. Vale ressaltar que todos os princípios éticos da Resolução n. 466/2012 do Conselho Nacional de Saúde (CNS) foram respeitados e que todos os participantes assinaram o Termo de Consentimento Livre e Esclarecido (TCLE). Os critérios de qualidade para estudos qualitativos, Consolidated Criteria for Reporting Qualitative Research (COREQ), foram utilizados neste estudo.

\section{Resultados}

Entre os 17 cuidadores informais familiares de idosos fragilizados residentes na área de abrangência da ESF, que participaram do estudo, a maioria era mulher (15; 88\%), casada (8; 47,1\%), católica $(10 ; 58,8 \%)$. A cor autodeclarada foi: branca $(6 ; 35,3 \%)$, parda $(6 ; 35,3 \%)$, preta $(4 ; 23,5 \%)$ e indígena $(1 ; 5,9 \%)$. A média de idade foi de 44,5 anos, com variação de 26 a 79 anos, e baixo nível de escolaridade (7; 41,2\% com ensino fundamental incompleto). A maior parte dos cuidadores residia com o idoso no mesmo domić́lio (12; 70,6\%) e tinha pelo menos um filho $(15 ; 88,2 \%)$. Em relação ao grau de parentesco, $12(70,6 \%)$ eram filhos do idoso. Sobre a atividade de lazer dos cuidadores, predominaram ver televisão $(10 ; 58,8 \%)$ e ir à igreja $(5 ; 29,4 \%)$.

Em relação à condição de saúde, embora a maioria dos cuidadores tivesse avaliado a própria saúde como boa ou muito boa (13; 76,5\%), ainda assim, 8 (47,1\%) eram diabéticos ou portadores de doenças cardiovasculares e este mesmo percentual fazia uso de, pelo menos, um medicamento diariamente. Dentre os cuidadores, 10 (58,8\%) informaram que nunca fizeram cirurgia e 12 (70,6\%) nunca precisaram ser internados. Apenas $3(17,7 \%)$ possuíam plano de saúde privado.

No concernente às entrevistas do estudo, as quais exploraram a vivência do cuidador informal familiar de idoso fragilizado, bem como a interação com a equipe de saúde da ESF, a análise temática das respostas evidenciou duas categorias: Relação de cuidado entre cuidador e idoso e Interação entre cuidador e Estratégia Saúde da Família.

\section{Relação de cuidado entre cuidador e idoso}

No contexto da relação de cuidado entre o cuidador familiar e o idoso, foi possível identificar um aspecto importante, quando se trata do respeito e da percepção da autonomia do idoso pelos cuidadores. Isto é, em vários discursos, o idoso foi comparado a uma criança que não tinha e/ou não podia decidir por si só ou, ainda, que não tinha desejos próprios. Este achado pode ser exemplificado com as seguintes falas:

[...] além de virar criança, ele não aceita as coisas que vocêf fala. (CI-1).

[...] eles viram crianças de novo e eles não aceitam nada do que você fala. (CI-3).

[...] bem mais complicado do que uma criança, né? Porque são teimosos. Familia é pior ainda, porque as coisas, eles não aceitam muito, né? (CI-5).

Por outro lado, uma característica evidenciada no presente estudo é que idosos fragilizados bem integrados ao convívio familiar têm a sua autonomia respeitada, quando ainda se encontra preservada. Esta perspectiva pode ser exemplificada na fala a seguir:

[...] o fato de eu conhecê-los desde pequeno, desde quando eu era pequena, então, sim, sei o que eles gostam, sei que eles não gostam, e eu procuro respeitar o que eles gostam e o que eles não gostam... (CI-4).

Nesse contexto de diminuição ou perda da autonomia do idoso, a jornada de cuidado dispensada pelo cuidador torna-se ainda mais intensa e requer desse indivíduo bastante paciência, principalmente quando o idoso apresenta incapacidade cognitiva. Ter paciência no cuidado foi mencionado por alguns cuidadores entrevistados:

[...] dá trabalho, né, mas tem que ter paciência, né? Tem que entender que, como se diz, né, eles estão no tempo deles, porque teima muito, né? Então, geralmente, é meio desobediente, quer fazer as coisas que não pode, né? (CI-7).

[...] a gente, primeiramente, ter paciência, né? Porque precisa ter muita paciência, ter paciência e cuidar conforme a necessidade, né, da pessoa, né? ... tem que ter muita paciência. Ainda mais se for um idoso igual é minha mãe, portadora de Alzheimer. Primeiro lugar é a paciência, calma, muita calma, gostar mesmo de tá cuidando, porque desgasta muito com a gente, com a familia toda. (CI-15). 
Outro ponto abordado pelos cuidadores foi a sobrecarga decorrente da função de cuidar do idoso familiar fragilizado, com consequente sentimento de abdicação dos projetos de vida para assumir a função de cuidar. Este contexto pode ser percebido nas falas a seguir:

Troca, carrega, dá banbo. Aí você, porque sua atenção tem que ser toda voltada ao idoso. Você não tem, na verdade, você não tem vida própria... tanto é que não casei por cuidar, né? Abri a mão, abri mão disso também... (CI-1).

Nós somos onze filhos, mas sempre sobra pra um né? Então, eu tenho que abrir mão de muita coisa. (CI-10).

Facilidades desse cuidado ou as dificuldades, porque eu não posso sair de casa [riso]. (CI-12).

[...] igual aconteceu vários episódios comigo de familia, de próprios filhos meus. Às vezes, eu ter que deixar de dar um pouco de atenção pra estar cuidando mais e, principalmente, o relacionamento com marido também, que fica complicado. Porque ele cobra muito as coisas e, às vezes, você não tem tempo nem pra ele. (CI-15).

A falta de capacitação e de habilidade técnica/instrucional para exercer o cuidado com o idoso foi outro ponto evidenciado nos discursos dos entrevistados:

Eu nunca recebi informação de nada não. É só prática mesmo, né? O dia a dia. (CI-2).

[...] por que não tenho formação e, além de não ter informação [...] (CI-10).

Embora o cuidado com o idoso fragilizado seja extenuante e possa causar dificuldades no manejo e sentimentos negativos, há de se considerar que é uma função que também traz sentimentos positivos, sobretudo de gratidão, sentido de vida e amor, principalmente por se tratar do cuidado de um ente idoso familiar. Alguns desses sentimentos podem ser identificados nas seguintes falas:

Útil. Eu me sinto útil, porque eu ajudo uma pessoa, né, que não está conseguindo. Pra mim, é muito bom, muito gratificante... (CI-4).

Ah! Eu me sinto viva! Eu me sinto, eu sinto que posso fazer algo por alguém, principalmente meus pais. (CI-6).

Me sinto bem. É bom a gente ser útil, né? (CI-7).

É muito gratificante! É muito bom pra gente, pro próprio ego da gente mesmo. (CI-15).
Interação entre cuidador e Estratégia Saúde da Família

Os cuidadores informais familiares participantes desta pesquisa identificaram questões pertinentes sobre sua interação com a ESF. Entre elas, destacou-se a comunicação efetiva entre o cuidador e a equipe, sobretudo por meio da visita domiciliar (VD) do Agente Comunitário de Saúde (ACS), o que pode ser percebido nas seguintes falas:

Olha, pra falar verdade, tem a mulher do posto, a Helena,
que teve um período bom com a gente aqui, que ela aju-
dou, facilitando fazer a carteirinha do posto. Ela está
fazendo visita periódica, perguntando como que ele es-
tava. E isso aí me ajudou muito, porque a gente viu que
ele precisava de uma atenção, e ela conseguiu dar. Ela
conseguiu marcar exame, isso ajudou. Os exames foram
mais rápidos com a presença dessa mulher do posto, a
Helena. Então, ela me ajudou bastante. (CI-11).

Olha, eu acho que as visitas são muito importantes, né? Igual a Lena, vem sempre que dá, faz visita, conversa com a vó. Eu acho muito importante esse ponto, porque passa segurança pra gente, em um caso de extrema necessidade, e passa também confiança, né, que a gente, que um caso de emergência, a gente pode estar contando com pessoal do posto. (CI-13).

Por que o pessoal fala o quê? O que a gente tem que fazer, as vacinas que o idoso tem que tomar, época das vacinas da gripe, né? Os cuidados. Oh, sua mãe tem que fazer o exame tal! Liga pra gente, marquei o exame pra sua mãe, marquei o médico pra sua mãe. Então, eu acho o pessoal do posto muito atencioso até. (CI-14).

Em questão de orientações que eu preciso, que não sei, eles me dão. Os cuidados com a ferida úlcera venosa também, eles acompanham, trazendo medicação, as receitas também a tempo e a hora, não falta. Médico acompanha de perto, enfermeiro. É, realmente, não tem o que queixar de nenbum deles. (CI-15).

Em contrapartida, como ponto negativo na interação entre o cuidador e a ESF, os discursos a seguir destacaram a rotatividade dos profissionais na equipe:

[...] porque, às vezes, a gente vai lá nem sempre tem médico, nem sempre tem enfermeira [...] (CI-4).

[...] que o PSF [Programa Saúde da Família] Santos Dumont fica muito tempo sem médico, né? (CI-12).

Assim, chamou a atenção, como consequência da frequente rotatividade dos profissionais de saúde, o déficit na assistência decorrente, sobretudo, da escassez de recursos humanos e da demanda volumosa de assistência. Este fato é evidenciado no discurso de um dos cuidadores: 
É, talvez visitas domiciliares fossem assim. Ver se está certo, como que é, auxilia a gente, igual vocêfalou. Talvez isso seria melhor, né, se fosse, né? Mas é difícil, né, porque são poucos profissionais. A gente sabe a demanda como que é. (CI-11).

\section{Discussão}

Conhecer as características dos cuidadores informais familiares de idosos, sobretudo daqueles já fragilizados, bem como compreender o cuidado e a interação com a equipe de saúde na visão desses indivíduos que cuidam, é oportuno para vislumbrar melhores condições de cuidado com o idoso e de autocuidado, uma vez que estas diferem de acordo com os distintos contextos. Por se tratar de uma população de vulnerabilidade social e econômica, na qual os cuidadores do estudo estão inseridos, há de se considerar que aspectos sociais, culturais e econômicos interfiram muito na dinâmica do cuidado com o idoso fragilizado. A falta de recursos financeiros para o cuidado formal, a responsabilização das mulheres pelo cuidado prestado aos idosos e não buscar auxílio profissional para este cuidado podem favorecer a perpetuação de uma cultura de cuidado com o idoso sem conhecimentos específicos para tal e com excessiva sobrecarga física e emocional do cuidador, mesmo e principalmente sendo um cuidador familiar ${ }^{(3)}$.

Chama a atenção no estudo, o fato de o cuidado ser majoritariamente exercido por mulheres e filhas dos idosos, o que confirma a premissa de que esta atividade é centrada na figura feminina dentro do núcleo familiar. Com a intensidade da demanda de atenção com o idoso, pode-se constatar que essas cuidadoras abdicam do desempenho de funções, como estudar ou trabalhar formalmente e até mesmo de constituir sua própria família, deixando de casar e ter filhos, para dedicar-se à prestação do cuidado. Como em um efeito cascata, essa prioridade na função de cuidar também impossibilita o acesso a atividades de lazer e distração. Algumas vezes, para adaptar-se à nova rotina de cuidados, a cuidadora que já é casada e/ou reside em casa independente muda-se para a casa do idoso ou leva-o para o seio de sua família, visando facilitar o desempenho das atividades. Aspectos como este, em que a maioria dos cuidadores familiares é do sexo feminino, abdica da vida pessoal e apresenta sobrecarga de tarefas ao cuidar, são fatores que vão ao encontro de outro estudo também realizado em Minas Gerais ${ }^{(3)}$.

Os cuidadores do estudo realmente destacaram a sobrecarga física e mental decorrente da função de cuidar do idoso familiar fragilizado, com consequente sentimento de abdicação dos projetos de vida para exercer esta função. Nem sempre o cuidador informal familiar teve a opção de escolha ou tem algum conhecimento para desenvolver essa tarefa ${ }^{(13)}$. De repente, o cuidador familiar depara-se com o desafio de conciliar a nova função com as demais atividades já inseridas na sua rotina, como emprego formal e atividades domésticas ${ }^{(14)}$. Essa situação de sobrecarga física e mental pode ser agravada pela falta de capacitação adequada ${ }^{(3)}$, além de repercutir negativamente na sua saúde ${ }^{(14)}$.

De fato, com o passar do tempo, a saúde do cuidador vai debilitando devido ao seu próprio processo de envelhecimento, quando surgem as DCNTs, ou ainda devido à prática exaustiva de cuidado com o idoso aliada ao desempenho das demais tarefas domésticas. Muitas vezes, essa rotina extenuante não lhe permite buscar por cuidados da sua própria saúde, levando a consequente piora de seu quadro. A vivência de cuidar do idoso com a saúde debilitada, aliada à sobrecarga física, também pode levar o cuidador familiar a comprometer sua saúde emocional ${ }^{(13)}$.

Nesta perspectiva de alta e exaustiva demanda do cuidar, emergiram falas dos cuidadores do estudo sobre o fato de que é preciso ter bastante paciência no cotidiano de cuidado prestado ao idoso. As demências resultantes do prejuízo cognitivo, que trazem alterações psicomotoras, funcionais e comportamentais, além dos danos na memória, demandam muita atenção e complacência do cuidador, pois, nesse estágio, o idoso necessita de cuidados básicos, como banho, higiene pessoal e alimentação ${ }^{(15)}$.

No contexto do presente estudo, os idosos fragilizados eram acometidos sobretudo pelas síndromes demenciais, o que os tornavam incapacitados para decidir sobre a própria vida, pois 
os levavam a uma decadência cognitiva progressiva, comprometendo as habilidades de pensar, expressar sentimentos, percepções, lembranças e raciocínio ${ }^{(16)}$. Isto favorece a incorporação do paternalismo do cuidador, fazendo com que ele mesmo, com frequência, tome as decisões tidas como mais ideais e adequadas ao idoso fragilizado, ferindo a sua autonomia ${ }^{(17)}$. Algumas das falas dos cuidadores familiares mostraram a perda de autonomia do idoso justamente por consequência da incapacidade cognitiva ou até mesmo em razão da interferência excessiva do próprio cuidador nas atividades. O declínio do desempenho das atividades de vida diária e da tomada de decisão pelo idoso requer uma supervisão atenta e assertiva durante os cuidados prestados, para que a autonomia dele não seja anulada $^{(16)}$.

Ademais, pôde-se perceber, nas entrevistas, que a nova rotina de atividades exercida durante o cuidado com o idoso fragilizado muitas vezes era desconhecida pelo cuidador familiar. Este, por vezes, não tinha habilidade técnica ou não recebera informações suficientes para o desempenho adequado do cuidar. Estas circunstâncias também foram evidenciadas no estudo desenvolvido em Minas Gerais ${ }^{(3)}$, no qual cuidadores familiares de pacientes em cuidados paliativos no domicílio viam-se diante de situações de cuidado desconhecidas, como: movimentação e higienização do idoso no leito, preparo e administração de medicamentos e alimentação, manuseio de drenos e sondas, realização de curativos, dentre outros. Estas habilidades, ao serem desconhecidas pelo cuidador, geram dificuldades e angústias no ato de cuidar ${ }^{(18)}$. Além disso, o fato de o cuidador não receber orientações/informações adequadas e suficientes para a realização do cuidado é indicativo de uma limitação no suporte dispensado pelas equipes de saúde a esses indivíduos ${ }^{(19)}$.

Dentre os diversos sentimentos expressados pelos cuidadores deste estudo, aqueles que remetem ao sentido da vida, sobretudo os sentimentos de ser útil para a outra pessoa e de gratidão no desempenho do cuidado, foram os que chamaram a atenção nas entrevistas. Outros estudos também corroboram esses achados, ao destacarem que esses sentimentos enaltecem os cuidadores e os motivam para a rotina de cuidado, além de estreitarem a relação do binômio cuidador/idoso. Ademais, tendo em vista que são cuidadores familiares, poder retribuir um pouco de tudo o que o idoso fez na vida pelo cuidador também traz satisfação ${ }^{(19-20)}$.

De modo geral, no que se refere à interação com a ESF, nenhum dos cuidadores do estudo mencionou algum acompanhamento sistematizado por parte da equipe de saúde voltado para o suporte técnico ou educacional do próprio cuidador, para o desenvolvimento das atividades inerentes ao cuidado. O que se pode perceber é que as ações da ESF estavam direcionadas para a demanda do idoso fragilizado e não para aquele que cuida dele. Vale salientar que um estudo de reflexão acerca da integralidade do cuidado prestado ao idoso reforça que um olhar especial dos profissionais para além do idoso que está sendo cuidado, isto é, um olhar voltado ao cuidador, torna-se essencial para que o cuidado oferecido seja de qualidade e humanizado. Do mesmo modo, este cuidador também deve ser assistido com estratégias que alcancem, ou pelo menos minimizem, os impactos na sua saúde. Quando os cuidadores contam com suporte estruturado e contínuo no cuidado, podem permanecer inseridos socialmente, sem se sentirem anulados pela sobrecarga extenuante do cuidar ${ }^{(11)}$.

As entrevistas revelaram que a ESF, juntamente com os cuidadores informais familiares de idosos fragilizados, encontrou situações desafiadoras no que tange ao manejo do cuidado a esse público, como, por exemplo, a rotatividade dos profissionais da equipe, prejudicando a criação de vínculo e, consequentemente, trazendo como desfecho um déficit na assistência. Por outro lado, um ponto favorável que pode ser observado nas falas dos cuidadores é a atuação do agente comunitário de saúde, o qual facilita a comunicação e a interação dos cuidadores familiares com a equipe, favorecendo um cuidado de mais qualidade.

A comunicação faz parte da essência humana. Desde o seu surgimento, o homem comunica-se 
com os meios disponíveis ${ }^{(21)}$. No âmbito da saúde, além da escuta qualificada, a comunicação permite acolhimento, esclarecimento, partilha e troca de saberes ${ }^{(22)}$, o que favorece o vínculo entre a equipe e o cuidador familiar de idosos, como evidenciado no presente estudo.

No concernente ao cenário da ESF, muitas vezes, o primeiro contato entre o cuidador familiar e a equipe de saúde dá-se por meio do ACS, uma vez que este profissional trabalha diretamente inserido na comunidade, conforme estabelecido pela $\mathrm{PNAB}^{(10)}$. O que se percebeu no presente estudo foi que o ACS tornou-se uma ponte entre o binômio cuidador/idoso e a equipe de saúde. Uma vez criado o vínculo, esse profissional tornou-se referência da equipe para o cuidador, propiciando comunicação efetiva e continuidade do cuidado. Tais constatações foram evidenciadas em um estudo de revisão bibliográfica, ao mostrar que uma comunicação efetiva entre o cuidador informal e a equipe de saúde é de extrema relevância para se conhecer o contexto no qual o indivíduo está inserido, permitindo uma resposta eficaz às suas demandas e proporcionando uma assistência resolutiva $^{(21)}$.

De acordo com pesquisa realizada no interior de São Paulo ${ }^{(11)}$, outro aliado da comunicação eficaz entre o binômio cuidador/idoso e a equipe de saúde, também notado neste estudo, foi a VD. Por meio dela, é possível identificar as singularidades apresentadas pelo idoso fragilizado, além de aproximar a equipe do cuidador informal e construir uma relação de confiança, possibilitando um vínculo mais sólido.

Em contrapartida, aspectos negativos observados, como a rotatividade dos profissionais da ESF, enfraquecem o vínculo da equipe com os usuários da rede, proporcionando, muitas vezes, uma assistência fragmentada e não resolutiva. Este fato, também evidenciado em outro estudo ${ }^{(23)}$, mostra que a rotatividade, principalmente dos profissionais médico e enfermeiro, compromete a qualidade da assistência e a satisfação da população adscrita. Os motivos de tamanha rotatividade decorrem de fatores econômicos, sociais, políticos, realização profissional entre outros, o que leva a resultados negativos e desfavoráveis aos usuários do serviço de saúde ${ }^{(24)}$.

Este problema de escassez de profissionais de saúde é realmente um grande desafio em diversos contextos. Em muitas situações, a ESF tem que trabalhar com equipe mínima, devido à rotatividade dos funcionários, o que leva à sobrecarrega de determinados profissionais da equipe, como, por exemplo, o enfermeiro ${ }^{(23)}$. Esta realidade foi identificada em uma pesquisa de reflexão sobre a complexidade do trabalho do enfermeiro na APS ${ }^{(25)}$, na qual evidenciou-se a sobrecarga de trabalho, devido ao acúmulo de funções. Uma equipe sem condições mínimas de trabalho, atuando com falta de recursos humanos, pode constituir-se em dificultador do acesso do usuário ao serviço de saúde. No caso da assistência ao idoso fragilizado, essa ocorrência fere uma das diretrizes do SUS, que é a longitudinalidade do cuidado.

Vale salientar que, nesta perspectiva de déficit assistencial, sobretudo de recursos humanos, os objetivos da APS, conforme proposto pela PNAB, ficam comprometidos. Isto é, o conjunto de ações no âmbito individual e coletivo, que abrange a promoção e a proteção da saúde, previne agravos, diagnostica, trata, reabilita e promove a manutenção da saúde, não será desenvolvido como preconizado ${ }^{(10)}$.

Compreender esse cenário e as percepções dos cuidadores familiares, sejam elas negativas ou positivas, bem como as potencialidades e os desafios que esses indivíduos enfrentam em seus cotidianos de cuidado é de extrema relevância para que a ESF possa planejar suas ações, mesmo que seja com uma população de estudo pequena, como ocorreu nesta pesquisa. Por isso, ressalta-se como limitações do estudo ter envolvido apenas uma equipe de ESF do município e ter como entrevistadora uma profissional atuante na ESF, o que pode ter interferido nos discursos sobre a relação com a instituição. Então, sugere-se que futuros estudos envolvam todas as equipes das ESF do município e que os entrevistadores não façam parte da equipe.

O presente estudo contribui para o conhecimento em saúde, ao fornecer subsídios para 
melhor compreensão da interação entre a ESF e o cuidador informal familiar de idoso fragilizado, colaborando para a reestruturação do processo de trabalho e, consequentemente, para o aperfeiçoamento da assistência prestada ao binômio cuidador/idoso. Especificamente em relação ao contexto da enfermagem, este estudo denota fragilidades e potencialidades, no que tange ao cuidado com a população idosa e seus cuidadores familiares, que podem suscitar ações de enfermagem direcionadas para a elaboração de planos singulares terapêuticos mais eficazes.

\section{Considerações finais}

$\mathrm{Na}$ perspectiva dos cuidadores informais, o estudo permitiu compreender que o cuidado prestado ao idoso fragilizado suscita um misto de sentimentos no cotidiano do cuidar, com predominância da gratidão por exercer esta função, mas também sobrecarga e cansaço com o cuidar diário. Mesmo sendo grato por poder desempenhar esse cuidado, o estudo mostrou que o cuidador compartilha o entendimento de que é preciso ter paciência no cuidado para com o idoso fragilizado e todos os seus desafios, sobretudo quando a incapacidade cognitiva avança. Ademais, observou-se que os cuidadores pertenciam ao universo feminino e vivenciavam mudanças em suas rotinas diárias que acabavam por gerar sobrecarga física e mental, além da abdicação de seus projetos de vida.

O estudo mostrou também que a falta de capacitação e de habilidade técnica por parte do cuidador familiar foram fatores que implicaram em insegurança para desempenhar o cuidado do idoso fragilizado. Nesse contexto, chamou a atenção, nas falas dos cuidadores, a anulação da autonomia do idoso durante o cuidado. No entanto, em contrapartida, quando o cuidador informal era um membro da família e o idoso era bem inserido no convívio familiar, sua autonomia era preservada.

No que tange à interação entre a ESF e o cuidador informal familiar de idosos fragilizados na área de abrangência estudada, evidenciou-se que essa interação acontecia, sim, e que, por vezes, se dava por meio da comunicação efetiva entre a equipe e o cuidador, mediada pelo ACS. Vale salientar que esse profissional é visto como fundamental na construção do elo entre a equipe de saúde e o binômio cuidador/idoso na área de abrangência estudada. Observou-se também que a alta rotatividade dos profissionais da equipe, juntamente com a demanda excessiva de funções desempenhadas por determinados membros, foram fatores de insatisfação da assistência prestada aos idosos e a seus cuidadores.

\section{Colaborações:}

1 - concepção, projeto, análise e interpretação dos dados: Mírian Aparecida de Lacerda, Liliane de Lourdes Teixeira Silva e Kellen Rosa Coelho;

2 - redação do artigo e revisão crítica relevante do conteúdo intelectual: Mírian Aparecida de Lacerda, Liliane de Lourdes Teixeira Silva, Flávia de Oliveira e Kellen Rosa Coelho;

3 - aprovação final da versão a ser publicada: Kellen Rosa Coelho.

\section{Referências}

1. Sampaio SN, Esteves AVF, Oliveira APP, Franco PC, Lima ES. Visão da pessoa idosa sobre o atendimento do enfermeiro da Atenção Básica. Rev baiana enferm. 2018;32:e27618. DOI: 10.18471/rbe.v32.27618

2. Medeiros KKAS, Coura AS, Ferreira RT. O aumento do contingente populacional de idosos no Brasil e a atenção primária à saúde: uma revisão de literatura. Arq Cienc Saúde UNIPAR. 2017;21(3):201-7. DOI: https://doi. org/10.25110/arqsaude.v21i3.2017.6034

3. Pessalacia JDR, Silva AE, Araújo DHQ, Lacerda MA, Santos KC. Experiências de cuidadores nos cuidados paliativos e redes de suporte. Rev enferm UFPE on line. 2018;12(11): 2916-22. DOI: https://doi.org/10.5205/1981-8963v12i11a236208p2916-2922-2018

4. Moraes EN. Atenção à saúde do idoso: aspectos conceituais [Internet]. Brasília (DF): Organização Pan-Americana da Saúde; 2012 [cited 2020 Nov 23]. Available from: https://apsredes.org/pdf/Saudedo-Idoso-WEB1.pdf 
5. Freire JCG, Nóbrega IRAP, Dutra MC, Silva LM, Duarte HA. Fatores associados à fragilidade em idosos hospitalizados: uma revisão integrativa. Saúde Debate. 2017;41(115):1199-211. DOI: http://dx.doi.org/10.1590/0103-1104201711517

6. Organização Mundial de Saúde, Organização Panamericana de Saúde. CIF - Classificação Internacional de Funcionalidade, Incapacidade e Saúde [Internet]. São Paulo: EdUSP; 2003 [cited 2020 Nov 23]. Available from: http://uniapae. apaebrasil.org.br/wp-content/uploads/2019/10/ CLASSIFICA\%C3\%87\%C3\%83O-INTERNACIONALDE-FUNCIONALIDADE-INCAPACIDADE-ESA\%C3\%9ADE.pdf

7. Santos SMC, Oliveira LS, Santos MCS, Carneiro SR, Santos LLS, Teodori RM. Avaliação da sobrecarga de trabalho e da qualidade de vida de cuidadores de idosos institucionalizados. Fisioter Brasil. 2017;18(4):433-41. DOI: http:// dx.doi.org/10.33233/fb.v18i4.1203

8. Oliveira NA, Souza EM, Luchesi BM, Inouye K, Pavarini SCI. Stress and optimism of elderlies who are caregivers for elderlies and live with children. Rev Bras Enferm. 2017;70(4):697-703. DOI: http://dx.doi.org/10.1590/0034-7167-2017-0088

9. Messias LAS, Gazetta FADA, Barbosa PMK, Calamita Z. Conhecimento prático e sobrecarga na vida de cuidadores de idosos com demência. Sci Med. 2018;28(3):ID30569. DOI: 10.15448/1980-6108.2018.3.30569

10. Brasil. Ministério da Saúde. Portaria no 2436, de 21 de setembro de 2017. Aprova a Política Nacional de Atenção Básica, estabelecendo a revisão de diretrizes para a organização da Atenção Básica, no âmbito do Sistema Único de Saúde (SUS) [Internet]. Brasília (DF); 2017 [cited 2020 Nov 23]. Available from: https://bvsms.saude.gov.br/bvs/ saudelegis/gm/2017/prt2436_22_09_2017.html

11. Santos SC, Tonhom SFR, Komatsu RS. Saúde do idoso: reflexões acerca da integralidade do cuidado. Rev Bras Prom Saúde. 2016;29(Supl): 118-27. DOI: https://doi.org/10.5020/18061230. 2016.sup.p118

12. Bardin L. Análise de conteúdo. São Paulo: Edições 70; 2011.

13. Nunes DP, Brito TRP, Duarte YAO, Lebrão ML. Cuidadores de idosos e tensão excessiva associada ao cuidado: evidências do Estudo SABE. Rev bras epidemiol. 2019;21(Suppl 2). DOI: https://doi.org/10.1590/1980-549720180020.supl.2
14. Rabelo ES, Lopes SC. A demência na terceira idade: a família no enfrentamento da doença, tendo como referência a ABRAz de São Luís, MA. Rev Bibliomar [Internet]. 2017 [cited 2020 Nov 23]:16(2):7-28. Available from: http://www.periodicoseletronicos. ufma.br/index.php/bibliomar/article/view/8806

15. Silva LB, Souza MFS. Os transtornos neuropsicológicos e cognitivos da doença de Alzheimer: a psicoterapia e a reabilitação neuropsicológica como tratamentos alternativos. Pretextos - Rev Grad Psicol PUC Minas [Internet]. 2018 [cited 2020 Nov 23];3(5):466-84. Available from: http://periodicos.pucminas.br/index.php/ pretextos/article/view/15987/13037

16. Scherrer Júnior G, Simão M, Passos KG, Ernandes RC, Alonso AC, Belasco AGS. Cognição prejudicada de idosos em instituições de longa permanência pública de São Paulo. Rev Enferm Brasil. 2019;18(3):339-48. DOI: 10.33233/eb.v18i3. 3085

17. Santos RAAS, Corrêa RGCF, Rolim ILTP, Coutinho NPS. Atenção no cuidado ao idoso: infantilização e desrespeito à autonomia na assistência de enfermagem. Rev Pesq Saúde [Internet]. 2016 [cited 2020 Nov 23];17(3):179-83. Available from: http://www.periodicoseletronicos. ufma.br/index.php/revistahuufma/article/ view/6793/4335

18. Silva MS, Beuter M, Benetti ERR, Bruinsma JL, Donati L, Girardon-Perlini NMO. Situações vivenciadas por cuidadores familiares de idosos na atenção domiciliar. Rev Enferm UFSM. 2019;9:e10. DOI: 10.5902/2179769232528

19. Coppetti LC, Giardon-Perlini NMO, Andolhe R, Dalmolin A. Produção científica da enfermagem sobre o cuidado familiar de idosos dependentes no domicílio. ABCS Health Sci. 2019;44(1):58-66. DOI: https://dx.doi.org/10.7322/abcshs.v44i1.1119

20. Gutierrez LLP, Fernandes NRM, Mascarenhas M. Caracterização de cuidadores de idosos da região metropolitana de Porto Alegre (RS): perfil do cuidado. Saúde debate. 2017;41(114):885-98. DOI: http://dx.doi.org/10.1590/0103-1104201711417

21. Andrade GB, Pedroso VSM, Weykamp JM, Soares LS, Siqueira HCH, Yasin JCM. Cuidados Paliativos e a importância da comunicação entre o enfermeiro e paciente, familiar e cuidador. Rev Fund Care Online. 2019;11(3):713-7. DOI: http://dx.doi.org/10.9789/2175-5361.2019. v11i3.713-717 
12

O cuidado com o idoso fragilizado e a Estratégia Saúde da Família: perspectivas do cuidador informal familiar

22. Cariolano-Marinus MWL, Andrade RS, Ruiz-Moreno L, Lima LS. Comunicação entre trabalhadores de saúde e usuários no cuidado à criança menor de dois anos no contexto de uma unidade de saúde da família. Interface. 2015;19(53). DOI: 10.1590/1807-57622013.0552

23. Tonelli BQ, Leal APR, Tonelli WFQ, Veloso DCMD, Gonçalves DP, Tonelli SQ. Rotatividade de profissionais da Estratégia Saúde da Família no município de Montes Claros, Minas Gerais, Brasil. RFO UPF. 2018;23(2):180-5. DOI: https://doi.org/10.5335/rfo.v23i2.8314

24. Mayer BLD, Hupper RE, Silva FS, Weiller TH, Poll MA. Profissionais de saúde da atenção

básica e a avaliação: revisão integrativa da literatura. Saúde (Santa Maria) [Internet]. 2015 [cited 2020 Nov 23];41(1):19-28. Available from: https://periodicos.ufsm.br/revistasaude/article/ viewFile/9209/pdf

25. Ferreira SRS, Perico LAD, Dias VRGF. A complexidade do trabalho do enfermeiro na Atenção Primária à Saúde. Rev bras enferm. 2018;71(supl1):752-7. DOI: http://dx.doi.org/10. 1590/0034-7167-2017-0471

Recebido: 18 de janeiro de 2021

Aprovado: 25 de maio de 2021

Publicado: 15 de julho de 2021

A Revista Baiana de Enfermagem utiliza a Licença Creative Commons - Atribuição-NãoComercial 4.0 Internacional.

https://creativecommons.org/licenses/by-nc/4.0/

Este artigo é de acesso aberto distribuído sob os termos da Licença Creative Commons (CC BY-NC).

Esta licença permite que outros remixem, adaptem e criem a partir do seu trabalho para fins não comerciais. Embora os novos trabalhos tenham de lhe atribuir o devido crédito e não possam ser usados para fins comerciais, os usuários não têm de licenciar esses trabalhos derivados sob os mesmos termos. 